\title{
Donor Site Evaluation after Full-Width Metatarsal Transfer for Metacarpal Reconstruction in Severe Thumb Hypoplasia: A Clinical Retrospective Study
}

\author{
Fan Bai \\ https://orcid.org/0000-0002-3332-6352 \\ Lu Liu \\ Department of Hand surgery, Beijing Ji Shui Tan Hospital \\ Qiuya Li \\ Department of Hand Surgery, Beijing Ji Shui Tan Hospital \\ Yunhao Xue \\ Department of Hand Surgery, Beijing Ji Shui Tan Hospital \\ Chen Yang \\ Department of Hand Surgery, Beijing Ji Shui Tan Hospital \\ Shanlin Chen ( $\nabla$ drcsl@qq.com ) \\ Department of Hand surgery, Beijing Ji Shui Tan Hospital
}

Peking University Fourth School of Clinical Medicine; Department of Hand Surgery,Beijing Ji Shui Tan Hospital

Research article

Keywords: Thumb hypoplasia, Reconstruction, Metatarsal transfer, Donor site, Morbidity, Outcome

Posted Date: October 13th, 2021

DOI: https://doi.org/10.21203/rs.3.rs-956311/v1

License: (c) (1) This work is licensed under a Creative Commons Attribution 4.0 International License. Read Full License 


\section{Abstract}

Background: Pollicization remains the default treatment for severe thumb hypoplasia, while the metatarsal transfer is an effective choice for metacarpal reconstruction, with competitive outcome of reconstructed thumb. However, rare researches focused on the outcome of donor foot of the metatarsal transfer. The purpose of this study was to evaluate the short-term outcome of donor foot after full-width metatarsal transfer for Manske Type IIIB and IV thumb hypoplasia.

Methods: Fourteen patients with Manske Type IIIB and IV thumb hypoplasia were enrolled in the study. A full-width metatarsal graft (vascularised, from the second metatarsal or non-vascularised, from the fourth metatarsal) was harvested; an adjacent half-width graft from the third metatarsal was transposed horizontally to replace the donor defect. Objective and subjective evaluations were performed at least 12 months postoperatively. The appearances of the toes and the radiographic findings of the metatarsals were evaluated by two authors, the length and width of the metatarsals were measured on digital anteroposterior radiographs using a paired sample t test. The parental satisfaction was evaluated using a self-administered questionnaire.

Results: Among these 14 patients (eight type $\varangle \mathrm{B}$ and six type $\nabla$ thumbs), there were ten male and four female patients. The mean age at operation was 34.2 months (range: 14 to 127 months), and the mean follow-up was 16.1 months (range: 12 to 30 months). Toe lengthening, toe overriding, and synostosis between the metatarsals were observed in two, two and two patients; toe shortening, toe deviation, metatarsal lengthening and metatarsal angulation were observed in one, one, one and one patient. The lengths of third and fourth metatarsals in donor site were significantly larger than those in contralateral side, while the widths of third and fourth metatarsals were not significantly different between donor and contralateral sides. The mean score in the parental satisfaction questionnaire (full score, 30) was 27.2, (range: 17 to 30), which rated as "good".

Conclusions: Following full-width metatarsal transfer for Type IIIB and IV thumb hypoplasia, transposition of the adjacent halfwidth metatarsal for donor reconstruction results in minor donor deficit and overall parenteral satisfaction.

\section{Level of evidence: $\otimes$}

\section{Background}

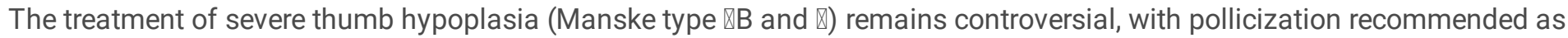
the default option by most surgeons.[1-6] However, there is growing expectations from parents to retain the hypoplastic thumb in preference of a five-digit hands.

There has been a recent increased number of reports regarding the reconstruction of severe thumb hypoplasia with the use of free metatarsal transfers. Tsujino et al. [7] reconstructed a thumb with a non-vascularised fourth metatarsal (MT), and the bone defect was filled by a full-thickness iliac bone graft. Chow et al. [8] reported on thumb reconstruction with hemi-longitudinal MT transfer in six cases, with good outcome of the reconstructed thumb and normal function the donor site, which reduced not only the sacrifice of the donor foot but also the strength of the reconstructed metacarpal. Despite the reported success of these various techniques in thumb function, $[5,7-13]$ the donor site morbidity has not been studied in detail.

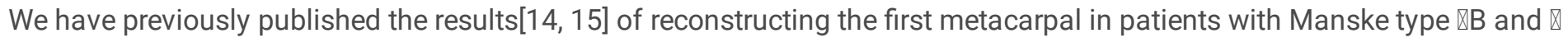
thumb hypoplasia using a non-vascularised graft of full-width fourth MT or vascularised graft of full-width second MT; the donor bone defect was filled with a hemi-width graft of the third MT. Thus, the aim of this study was to evaluate the outcome of the donor foot in our patients, after full-width transfer of the second or fourth MT for Manske type $\otimes B$ and $\otimes$ thumb hypoplasia.

\section{Methods}

\section{General information}


We retrospectively evaluated 14 feet of 14 paediatric patients following nonvascularised full-width fourth MT transfer or vascularised full-width second MT flap transfer for Manske type $\triangle B$ and $₫$ thumb hypoplasia from 2020 to 2021, with a followup duration of more than 12 months. Bilateral feet of each patient were normal preoperatively and only one foot of each patient underwent the MT transfer.

All parents were informed about the advantages and disadvantages of different procedures, including pollicization and MT transfers. The final choice was made by the parent.

\section{Surgical technique}

Surgical details had previously been described in previous articles. $[14,15]$ The toe harvest and reconstruction of donor foot is further elaborated here. The hypoplastic thumb was pulled after surgical preparation to measure the length of the bone defect at the recipient site. In non-vascularised fourth MT transfer, a longitudinal incision was made between the third and fourth MTs over the dorsum of the foot, an osteotomy was performed to harvest the full-width graft of the distal fourth MT, and the length of the graft was based on the bone defect at the recipient site. In vascularised second MT flap transfer, an oval-shaped flap was designed over the dorsum of the second MT. The incision was continued proximally to prepare the vessels, and an osteocutaneous flap was harvested in a manner similar to fourth MT transfer. In our practice, osteotomies were always performed proximal to the midpoint of the longitudinal axis of the donor MTs. A row of holes was drilled using a Kirschner wire (K-wire) $(0.8 \mathrm{~mm})$ along the longitudinal axis of the third MT, an osteotomy was performed with a scalpel, the adjacent halfwidth graft of the third MT was horizontally transposed to the bone defect at the donor MT, and the skin was closed. One or two K-wires $(0.8 \mathrm{~mm})$ were used to stabilise the reconstructed MT for 4 weeks postoperatively (Figure 1), the K-wires were removed and weight-bearing was allowed after the radiologic healing of reconstructed MT was achieved.

\section{Follow-up assessment}

For evaluation, the donor foot was compared with the normal contralateral foot. Each patient was examined by two of the authors (Fan Bai and Lu Liu), and the results of all assessments and measurements were made after agreement of both authors.

\section{Objective assessment}

For objective assessment, the following were measured:

Appearances of the second/fourth and third toes, reported as normal or nearly normal, lengthening, shortening, deformity and other anomalies.

Radiographic findings of the second/fourth and third MTs, reported as normal or nearly normal, delayed union or nonunion, synostosis between second/fourth and third MTs, deformity, lengthening, shortening and other anomalies on anteroposterior (AP) and oblique radiographs.

The measurement of the length and width of the second/fourth and third MTs in the donor site on digital AP radiographs, using the picture archiving and communication systems (Carestream Health, Shanghai, China) of our hospital. The MTs in the contralateral side were also measured as control. The length and width of the fourth MTs were analysed in patients who underwent fourth MT harvest procedure. The length and width of the second MTs were analysed in patients who underwent the second MT harvest procedure, and the length and width of the third MTs were analysed in all patients. The measurement strategy is shown in Figure 2.

In addition, the presence, location and extent of callus at the plantar pedis or toe dorsum and quality of hypertrophic scar were documented.

\section{Subjective assessment}


For subjective assessment, parental satisfaction was assessed using a self-administered questionnaire with reference to the Maryland Foot Score [16] and the American Orthopaedic Foot and Ankle Society (AOFAS) Lesser Toe MetatarsophalangealInterphalangeal Scale [17]. Some applicable questions and answers were selected for our new questionnaire, and those evaluating severe dysfunctions were eliminated due to the generally good outcomes reported by the patients. A more detailed classification criterion was applied to the responses to the new questionnaire to differentiate various degrees of mild morbidity. In addition, pain assessment required the parents to observe abnormal conditions in patients' daily activities and recall whether the patients complained of donor foot pain, which may reduce the accuracy of the response, so the weighting of this question was reduced.

The questionnaire consisted of the following items: (1) pain, (2) function of the donor foot, (3) appearance of donor foot, (4) overall range of active motion of toes in the donor foot, (5) treatment history or treatment plan for donor foot discomfort, (6) overall satisfaction with the appearance of the donor foot, (7) overall satisfaction with the function of the donor foot, and (8) comments. Items 1 to 4 had a four-scale scoring $(4,3,2$, and 0$)$, item 5 also had a four-scale scoring $(4,2,0$, and 0$)$, and items 6 and 7 had a five-scale scoring $(5,4,3,2$, and 0$)$, with a higher score indicating a better condition. The total score of the new questionnaire was 30: scores between 30 and 28 were classified as excellent, scores between 27 and 24 were good, scores between 23 and 19 were fair, and scores equal to or less than 18 were poor. The English version of the new questionnaire is presented in Additional file 1.

\section{Statistical analyses}

After the test for normal distribution, the mean and standard deviation (SD) of the lengths and widths of MTs were calculated. The lengths and widths of MTs were assessed using a paired sample t test. Statistical significance was set at $p<0.05$.

\section{Results}

Ten male and four female paediatric patients were evaluated. The mean age at operation was 34.2 (range: 14 to 127) months, the mean age at follow-up was 50.8 (range: 26 to 140) months, and the mean follow-up period was 16.1 (range: 12 to 30) months. There were eight Manske type $₫ \mathrm{~B}$ thumbs and six Manske type $₫$ thumbs. According to the modified classification (JST

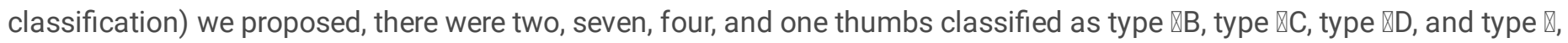
respectively. [18]Ten non-vascularised fourth MT grafts (five left and five right) and four vascularised second MT flap grafts (two left and two right) were harvested in first metacarpal reconstruction procedures. The demographic data of the patients are listed in Table 1 and the details are presented in the Additional file 2.

Table 1

Demographic data of patients.

\begin{tabular}{|c|c|}
\hline Patient information & Number \\
\hline Mean age at operation (month) & 34.2 (range: 14 to 127 ) \\
\hline Mean age at follow-up (month) & 50.8 (range: 26 to 140 ) \\
\hline Mean follow-up (month) & 16.1 (range: 12 to 30 ) \\
\hline Sex (male/female) & $10 / 4$ \\
\hline Manske type of thumb $(\mathbb{B} / \mathbb{\nabla})$ & $8 / 6$ \\
\hline 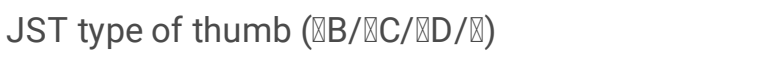 & $2 / 7 / 4 / 1$ \\
\hline Donor side foot (left/right) & $7 / 7$ \\
\hline Donor metatarsal and method ( $4 \mathrm{MT}^{\mathrm{a}} / 2 \mathrm{MT}$ flap $\left.{ }^{\mathrm{b}}\right)$ & $10 / 4$ \\
\hline
\end{tabular}




\section{Appearances of the toes}

Abnormal appearances of donor toes were observed in three patients. Lengthening and deformity of second/fourth toe were observed in two (patient no. 5 (P5) and P7) and one patient (deviation, P1); and shortening of third toe were observed in one patient (P7).

Unexpectedly, deformity of the nonsurgical second toe overriding on an adjacent toe was observed in two patients (P9, P10) after fourth MT transfer (Figure 3 and Table 2).

Table 2

Appearances and radiographic findings of objective assessment.

\begin{tabular}{|c|c|c|c|c|c|c|c|c|}
\hline & & Normal & Lengthening & Shortening & Deformity & Synostosis & Nonunion & $\begin{array}{l}\text { Other } \\
\text { anomalies }\end{array}$ \\
\hline \multirow[t]{2}{*}{ Appearances } & $\begin{array}{l}2 \mathrm{nd} / 4 \text { th } \\
\text { toe }\end{array}$ & 11 & 2 & 0 & 1 (deviation) & $\mathrm{N} / \mathrm{A}$ & $\mathrm{N} / \mathrm{A}$ & 0 \\
\hline & 3rd toe & 13 & 0 & 1 & 0 & $\mathrm{~N} / \mathrm{A}$ & $\mathrm{N} / \mathrm{A}$ & 0 \\
\hline \multirow[t]{2}{*}{$\begin{array}{l}\text { Radiographic } \\
\text { findings }\end{array}$} & $\begin{array}{l}\text { 2nd/4th } \\
\text { MT }\end{array}$ & 10 & 1 & 0 & $\begin{array}{l}1 \\
\text { (angulation) }\end{array}$ & 2 & 0 & 0 \\
\hline & 3rd MT & 12 & 0 & 0 & 0 & & 0 & 0 \\
\hline
\end{tabular}

\section{Radiographic findings of the donor MTs}

Abnormal radiographic findings of donor MTs were observed in four patients; synostosis between the second/fourth and third MTs were observed in two feet (P1 and P4); deformity and lengthening of second/fourth MT were observed in one (angulation, P2) and one (P7) patient respectively; abnormal appearances of third MT were not observed (Figure 4 and Table 2).

A slight hypertrophic scar was observed at one incision site (P3), and callus at the planta pedis or toe dorsum was not observed in any foot.

\section{Measurement of the donor MTs}

Eleven patients underwent AP radiography of the bilateral feet, including eight patients who underwent fourth MT transfer and three patients who underwent second MT transfer. The mean and SD of the length and width of the MTs are presented in Table 3. The lengths of the fourth and third MTs in the donor side were significantly larger than those in the contralateral side $(P=0.04$, and 0.03 , respectively). The length of the second MT on the donor side was not significantly different from that on the contralateral side $(P=0.32)$. The widths of the fourth, second, and third MTs in the donor side were not significantly different from those in the contralateral side $(P=0.98,0.69$, and 0.92 , respectively). 
Table 3. The length and width of the metatarsals and $t$ test between donor and contralateral side.

\begin{tabular}{|c|c|c|c|c|c|c|}
\hline & & \multicolumn{2}{|c|}{ Donor side } & \multicolumn{2}{|c|}{$\begin{array}{l}\text { Contralateral } \\
\text { side }\end{array}$} & \multirow{2}{*}{$\begin{array}{l}P \\
\text { value } \\
\text { of } t \\
\text { test }\end{array}$} \\
\hline & & $\begin{array}{l}\text { Mean } \\
(\mathrm{mm})\end{array}$ & SD & $\begin{array}{l}\text { Mean } \\
(\mathrm{mm})\end{array}$ & SD & \\
\hline \multirow[t]{3}{*}{ Length } & $\begin{array}{l}\text { 4th } \\
\text { MT }\end{array}$ & 34.38 & 7.13 & 32.81 & 6.14 & 0.04 \\
\hline & $\begin{array}{l}\text { 2nd } \\
\text { MT }\end{array}$ & 48.08 & 9.08 & 46.57 & 10.72 & 0.32 \\
\hline & $\begin{array}{l}\text { 3rd } \\
\text { MT }\end{array}$ & 37.13 & 8.83 & 36.00 & 9.92 & 0.03 \\
\hline \multirow[t]{3}{*}{ Width } & $\begin{array}{l}\text { 4th } \\
\text { MT }\end{array}$ & 4.32 & 1.00 & 4.33 & 0.46 & 0.98 \\
\hline & $\begin{array}{l}\text { 2nd } \\
\text { MT }\end{array}$ & 6.02 & 0.88 & 5.70 & 1.18 & 0.69 \\
\hline & $\begin{array}{l}3 r d \\
\text { MT }\end{array}$ & 4.80 & 1.28 & 4.78 & 1.02 & 0.92 \\
\hline \multicolumn{7}{|c|}{$\begin{array}{l}\text { Table 3. The measurement of 4th MTs included eight } \\
\text { patients, the measurement of } 2 \text { nd MTs included three } \\
\text { patients, and the measurement of 3rd MTs included } 11 \\
\text { patients. }\end{array}$} \\
\hline \multicolumn{7}{|c|}{ SD: standard deviation. MT: metatarsals. } \\
\hline
\end{tabular}

\section{Subjective assessment}

The mean score of the parental subjective questionnaire was 27.2 (range: 17 to 30), which was classified as 'good'. The score of questionnaire of nine (P1, P3-P4, P6, P8, P11-P14), three (P2, P5 and P7), one (P9) and one (P10) patient was respectively classified as excellent, good, fair, and poor. Pain was classified as 'slight' by two parents behalf of their children, the pain of P10 could not be precisely located, the pain of P13 was located at the incision site. Toe deformity was classified as 'slight' by four parents (those of P5, P7, P9, and P10); the range of active motion of the toes was classified as 'slightly limited' and 'obviously limited' by one (that of P5) and one (that of P3) parent; the foot function was classified as 'limited in daily activities' by one parent (that of P10).

There were 11 parents very satisfied or somewhat satisfied with both the general appearance and function of the donor foot. Other parents were asked for the reason of their lower satisfaction: the parent of P2 indicated 'fair' in terms of appearance and function without a clear reason, the parent of P9 responded 'somewhat dissatisfied' in terms of the appearance for the second toe overriding deformity, and the parent of P10 indicated 'fair' in terms of the appearance and function for the second toe overriding deformity and pain at the incision site.

The parents were also asked to fill out the Maryland Foot Score and the AOFAS Lesser Toe MetatarsophalangealInterphalangeal Scale; the mean scores were 96.23 (range: 76 to 100) and 97.15 (range: 80 to 100), respectively (Table 4). The scores rated by the parents in three questionnaires are presented in Additional file 3.

\section{Discussion}


MT transfer for reconstruction of the severely hypoplastic thumb is an increasingly popular option.[18] When counselling parents for MT reconstruction, the surgeon has to help them overcome two barriers to surgery, including the creation of an additional donor site in the body and the persistent dogma that pollicization may be seen as a better option. A minimal donor site may provide a stronger impetus for parents to choose this option over a pollicization. However, few studies have specifically examined the outcome and parental satisfaction of the donor foot.

Objective and subjective assessments of the donor foot are important for helping parents in their decision-making. Regarding objective assessments, we used items based on our experience and studies on donor site outcomes of toe phalangeal transfer $[19,20]$. However, we have found it difficult to evaluate the outcome of the donor foot in our series, because most of our patients were very young during the operation and follow-up; this rendered the assessment strategies developed for adults inapplicable. Gait analysis was also performed, but the data quality of most patients was too poor to be analysed.

In the objective assessment, we also observed mostly slight lengthening of the second or fourth toes without pain, calluses, or problems with wearing shoes. The morbidity of the third toes and third MTs was obviously less than that of the second and fourth toes and MTs; we presume that this is so because the third MTs were left in situ and usually not fixed with K-wires, reducing the likelihood of damage. Mild deviation without discomfort was also observed in one donor toe; however, overriding of the nonsurgical second toe on adjacent toe was unexpectedly found in two patients who had undergone fourth MT transfer, and the parents of both patients were planning to have this deformity corrected. There was no sign of crowded arrangement of other toes that was deemed responsible for this deformity, and its cause is still unknown. Thus, further study should be conducted to determine the primary cause. As the most common abnormal radiographic manifestation, synostosis between the second/fourth and third MTs was observed in two feet. There were no reports of associated discomfort or decreased range of active motion of toes; lengthening and curving of MTs were also occasionally observed, and no associated discomfort was reported; thus, we believe that slight morbidity, including the ones mentioned previously, is acceptable.

In the measurement of MTs, we found that the lengths of the fourth and third MTs in the donor feet were significantly larger than those in the contralateral feet, implying the overgrowth of MTs after surgery. However, we observed only the lengthening of the toe in two of the fourth toes, both with diminishing natural flexion-curve in the metatarsophalangeal and interphalangeal joints caused by K-wire fixation (Figure 3b). We attributed the 'lengthening' of the fourth and third toes to the diminished natural curve, by which the lengthening of MTs was not significant enough to influence the appearance of toes. The widths of the fourth and third MTs were not significantly different between the donor and contralateral sides, indicating a rapid width recovery of donor MTs, which also demonstrated their reliable strength. In addition, the length and width of the second MTs were not significantly different between the donor and contralateral sides, which may be attributed to the small sample size (three patients).

In the subjective assessment questionnaire, most parents were generally satisfied with the outcome of the donor foot. Scores of pain, function, and active motion range were excellent. Although four parents responded 'fair' to the question regarding the deformity of the donor foot, none was dissatisfied with the appearance of the foot in terms of the slight length change, implying that slight deformities were acceptable for most parents.

There were 12 patients with a score of 95 or above on the Maryland Foot Score and 11 patients with a score of 100 on the AOFAS Scale. The similar high scores in the Maryland and AOFAS questionnaires implied generally good patient outcomes, suggesting that these two questionnaires were unable to distinguish the patient outcomes in our series. In our new questionnaire, however, the scores of nine, three, one, and one patient were classified as excellent, good, fair, and poor, respectively. We believe that the new questionnaire could better distinguish the patient outcomes than the Maryland and AOFAS questionnaires. The parents of 11 patients were very satisfied or somewhat satisfied with both the appearance and function of the donor foot, all of which were classified as excellent or good. The parents of three patients indicated 'fair' or were somewhat dissatisfied with the appearance and/or function outcome(s), and the scores of two patients were classified as fair or poor. So, we believe that the score of the new questionnaire could generally reflect parental satisfaction in terms of appearance and function. In this study, we proposed an evaluation strategy, consisting of objective and subjective assessments, that is appropriate for very young patients. The outcomes of most patients were satisfactory. In patients with 
morbidity, the lengthening of donor toes and synostosis between involved MTs were common, but did not cause pain or dysfunction, and most parents were satisfied with the outcome. The lengths and widths of MTs were also measured using radiographs, and we found that there may be longitudinal overgrowth of the fourth and third MTs of the donor foot after operation, but the widths of the fourth and third MTs of the donor foot rapidly recovered. We believe that following metatarsal transfer for severe thumb hypoplasia, transposition of the adjacent half-width metatarsal for donor reconstruction results in minor donor deficit. However, further research is needed to examine the outcome of the donor foot after full-width MT transfer and to minimise donor foot morbidity.

This study had several limitations. First, most of our patients were too young to answer follow-up questions, so we had to assess the satisfaction of parents, which may result in the omission of some discomfort that patients cannot express. Second, the sample size of our series was small (especially for the measurement of MTs) and the follow-up period was short; thus, a long-term assessment of more patients is warranted to investigate the outcomes of the donor foot and the changes in the length and width of MTs in the future.

\section{Conclusions}

Following full-width metatarsal transfer for Manske Type IIIB and IV thumb hypoplasia, transposition of the adjacent half-width metatarsal for donor reconstruction results in minor donor deficit and overall parenteral satisfaction.

\section{Abbreviations}

MT: metatarsal

K-wire: Kirschner wire

AP: anteroposterior

AOFAS: American Orthopaedic Foot and Ankle Society

SD: standard deviation

\section{Declarations}

\section{Acknowledgements:}

We would like to thank Jie Shen for her assistance in this research.

\section{Author's Contributions:}

Fan Bai and Shanlin Chen researched literature and conceived the study. Fan Bai and Lu Liu evaluated the patients together. Lu Liu, Qiuya Li, Yunhao Xue and Chen Yang involved in, gaining ethical approval, patient recruitment and data analysis. Fan Bai wrote the first draft of the manuscript. All authors reviewed and edited the manuscript and approved the final version of the manuscript.

\section{Funding:}

The authors received no financial support for the research, authorship, and/or publication of this article.

\section{Availability of data and materials:}




\section{Ethical Approval and consent to participate:}

Ethical approval for this study was obtained from Institutional Review Board of Beijing Ji Shui Tan Hospital (202007-28).

Written informed consent was obtained from legally authorized representatives before the study. All clinical investigations had been conducted according to the principles expressed in the Declaration of Helsinki.

\section{Consent for publication:}

Consent for publication was obtained from every legally authorized representatives whose photos and data are included in this study.

\section{Competing interests:}

The authors declare that they have no competing interests.

\section{References}

1. Buck-Gramcko D. Pollicization of the index finger. Method and results in aplasia and hypoplasia of the thumb. The Journal of bone joint surgery American volume. 1971;53(8):1605-17.

2. Manske PR. Index pollicization for thumb deficiency. Tech Hand Up Extrem Surg. 2010;14(1):22-32.

3. Zlotolow DA, Tosti R, Ashworth S, Kozin SH, Abzug JM. Developing a pollicization outcomes measure. J Hand Surg. 2014;39(9):1784-91.

4. Tonkin MA. On the classification of congenital thumb hypoplasia. The Journal of hand surgery European volume. 2014;39(9):948-55.

5. Foucher G, Medina J, Navarro R. Microsurgical reconstruction of the hypoplastic thumb, type IIIB. J Reconstr Microsurg. 2001;17(1):9-15.

6. Tay SC, Moran SL, Shin AY, Cooney WP 3. The hypoplastic thumb. J Am Acad Orthop Surg. 2006;14(6):354-66. rd. .

7. Tsujino A, Itoh Y, Hayashi K. Reconstruction of floating thumb by transplanting the fourth metatarsal. The Journal of bone joint surgery British volume. 1994;76(4):551-4.

8. Chow CS, Ho PC, Tse WL, Hung LK. Reconstruction of hypoplastic thumb using hemi-longitudinal metatarsal transfer. The Journal of hand surgery European volume. 2012;37(8):738-44.

9. Nishijima N, Matsumoto T, Yamamuro T. Two-stage reconstruction for the hypoplastic thumb. J Hand Surg. 1995;20(3):415-9.

10. Shibata M, Yoshizu T, Seki T, Goto M, Saito H, Tajima T. Reconstruction of a congenital hypoplastic thumb with use of a free vascularized metatarsophalangeal joint. The Journal of bone joint surgery American volume. 1998;80(10):1469-76.

11. Tu YK, Yeh WL, Sananpanich K, Ueng SW, Chou YC, Ma CH, et al. Microsurgical second toe-metatarsal bone transfer for reconstructing congenital radial deficiency with hypoplastic thumb. J Reconstr Microsurg. 2004;20(3):215-25.

12. Schneider W, Reichert B, Pallua N, Meyer H. Correction of hypoplastic thumb by free transfer of metatarsal bone: a case report. Microsurgery. 1993;14(7):468-71.

13. Tan JS, Tu YK. Comparative study of outcomes between pollicization and microsurgical second toe-metatarsal bone transfer for congenital radial deficiency with hypoplastic thumb. J Reconstr Microsurg. 2013;29(9):587-92.

14. Tong D-D, Wu L-H, Li P-C, Rong Y-B, Liu B, Lee W, et al. Reversed vascularized second metatarsal flap for reconstruction of Manske type IIIB and IV thumb hypoplasia with reduced donor site morbidity. Chin Med J (Engl). 2019;132(21):2565-71. 
15. Liu B, Chen S, Chow ECS, Li P, Liu K, Yang C. Type IIIB and IV hypoplastic thumb reconstruction with non-vascularized fourth metatarsal. The Journal of hand surgery European volume. 2020;45(7):722-8.

16. Maryland Foot Score. J Orthop Trauma. 2006;20(8):96-S7.

17. Kitaoka HB, Alexander IJ, Adelaar RS, Nunley JA, Myerson MS, Sanders M. Clinical rating systems for the ankle-hindfoot, midfoot, hallux, and lesser toes. Foot Ankle Int. 1994;15(7):349-53.

18. Liu B, Bai F, Chen S. Revisiting the management of Manske Type 3B and 4 thumb hypoplasia. The Journal of hand surgery European volume. 2021;46(1):21-9.

19. Bourke G, Kay SP. Free phalangeal transfer: donor-site outcome. Br J Plast Surg. 2002;55(4):307-11.

20. Garagnani L, Gibson M, Smith PJ, Smith GD. Long-term donor site morbidity after free nonvascularized toe phalangeal transfer. J Hand Surg. 2012;37(4):764-74.

\section{Table}

Due to technical limitations, table 4 is only available as a download in the Supplemental Files section.

\section{Figures}




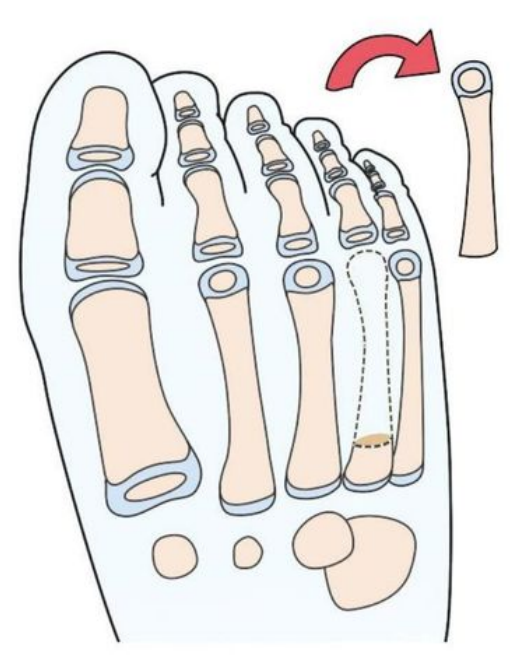

(a)

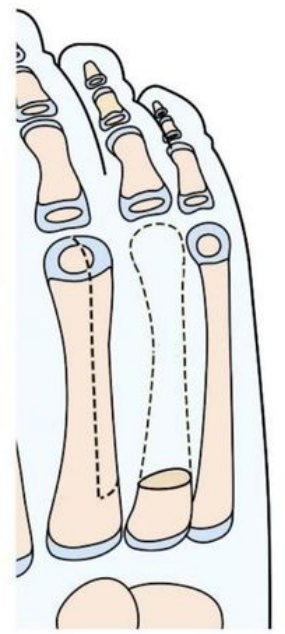

(b)

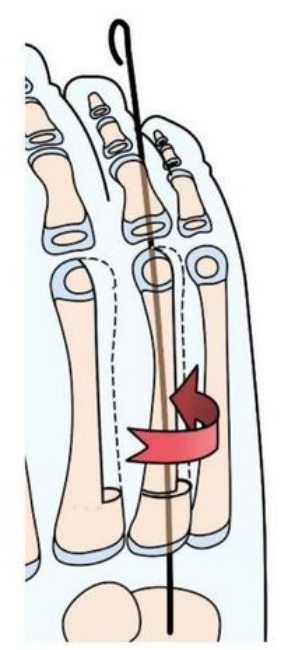

(c)

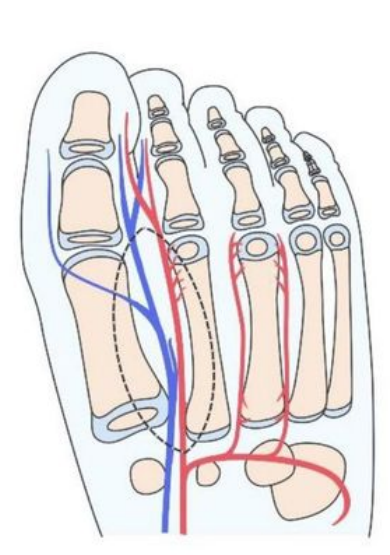

(d)

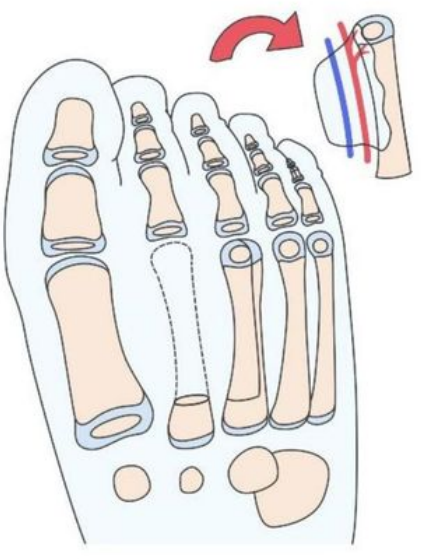

(e)

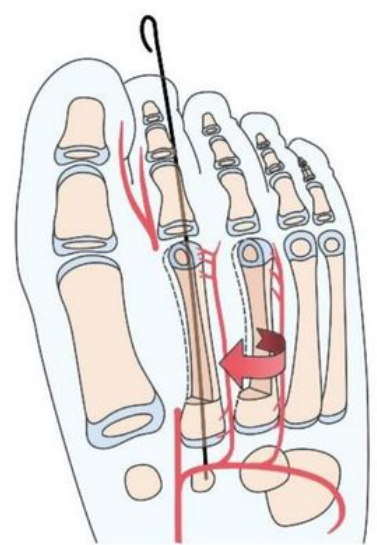

(f)

\section{Figure 1}

The harvest of full-width graft of fourth metatarsal (a), the osteotomy of the third metatarsal (b) and the reconstruction of donor bone defect using lateral half of third metatarsal (c) in non-vascularized fourth metatarsal transfer. The design of flap (d), the osteotomy of the second and third metatarsals (e) and the reconstruction of the donor bone defect (f) in vascularized second metatarsal transfer. 


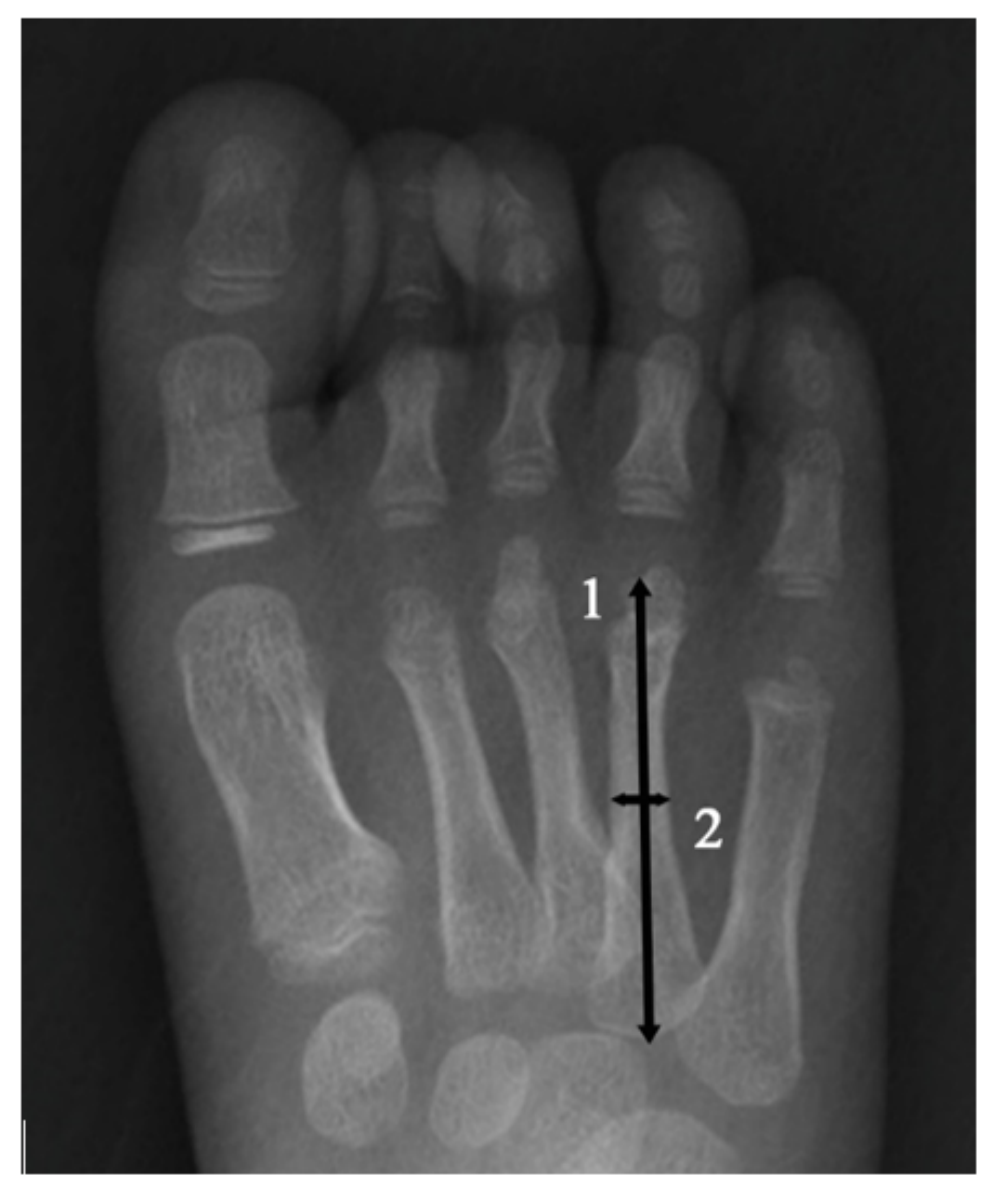

\section{Figure 2}

The measurement of the length and the width of metatarsal on anteroposterior X-ray film. The longitudinal axis of the metatarsal (line 1) was defined as the longitudinal axis of the bone shaft and line 2 was the midperpendicular of line 1. The length of metatarsal was the distance between proximal and distal margins of the articular surface on line 1 and the width of metatarsal was the distance between medial and lateral margins of the articular surface on line 2. 

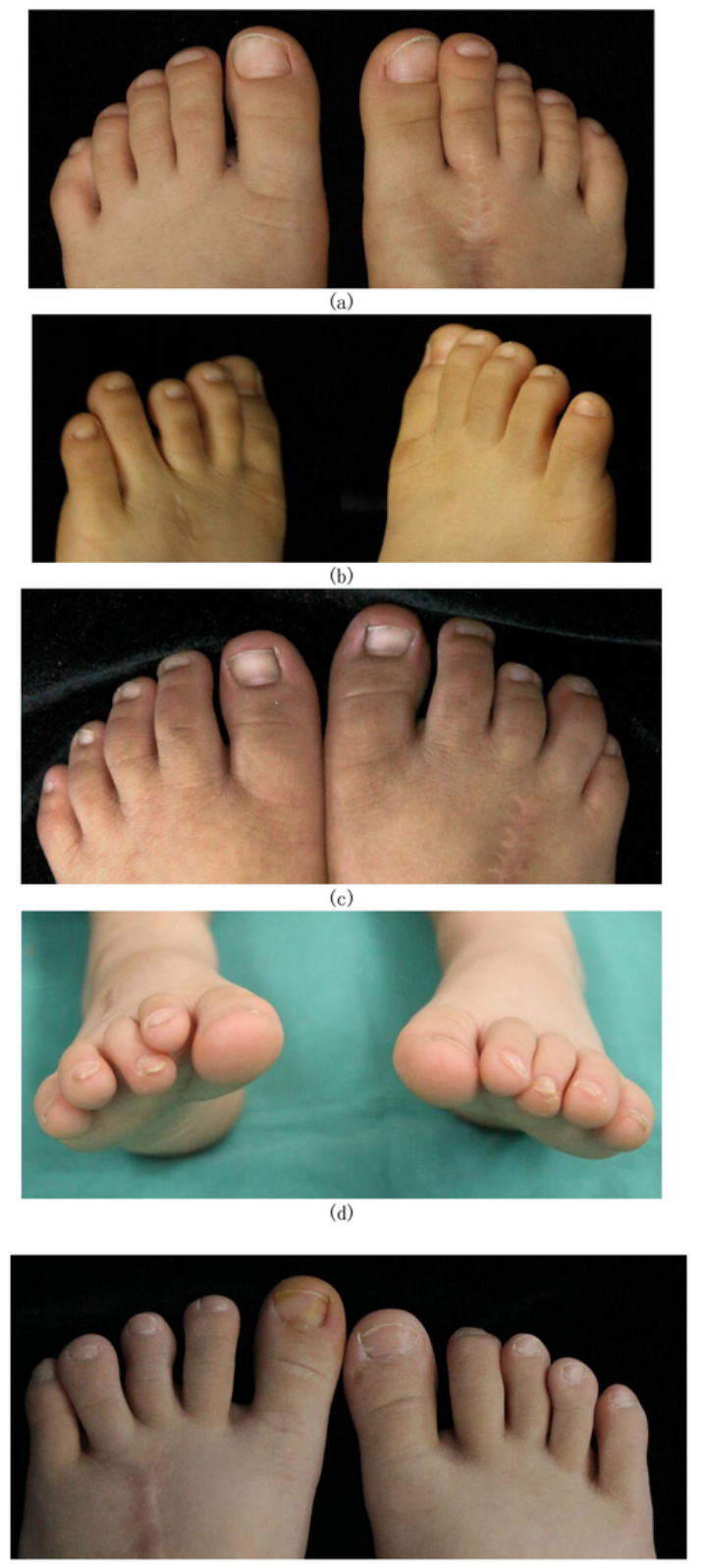

(e)

\section{Figure 3}

Appearance of the donor foot. (a) Normal right foot. (b) The lengthening and the diminished natural flexion-curve in metatarsophalangeal and interphalangeal joints of the left fourth toe. (c) The shortening of the right third toe. (d) The second toe overriding on the third toe after right fourth metatarsal transfer. (e) The lateral deviation of the left fourth toe. 


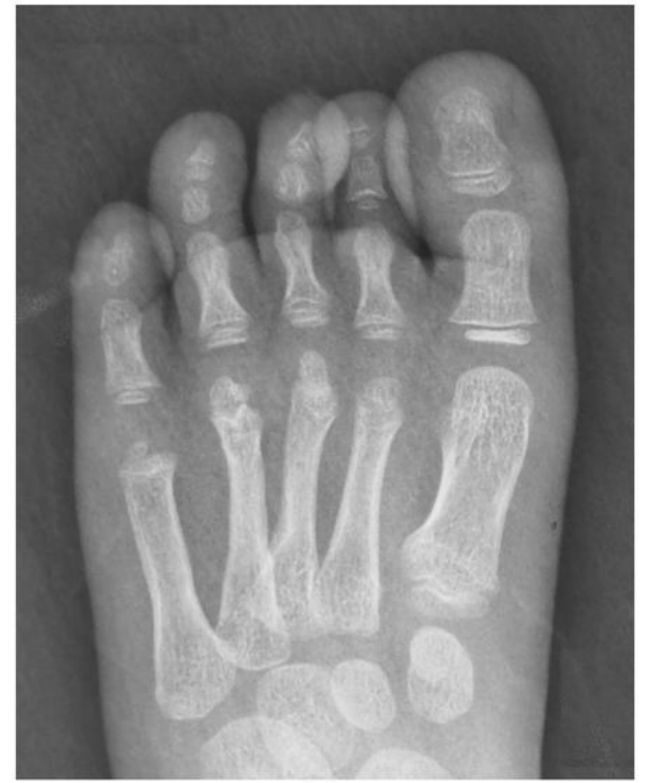

(a)

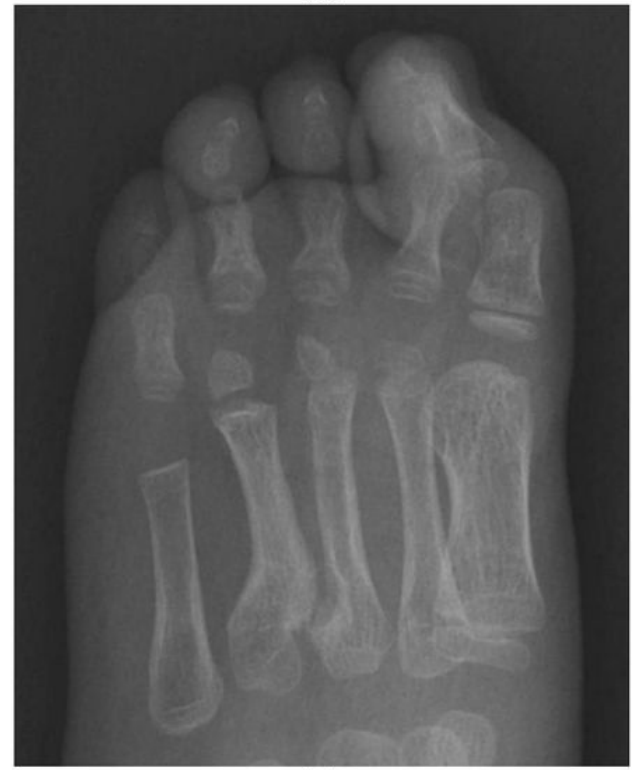

(c)

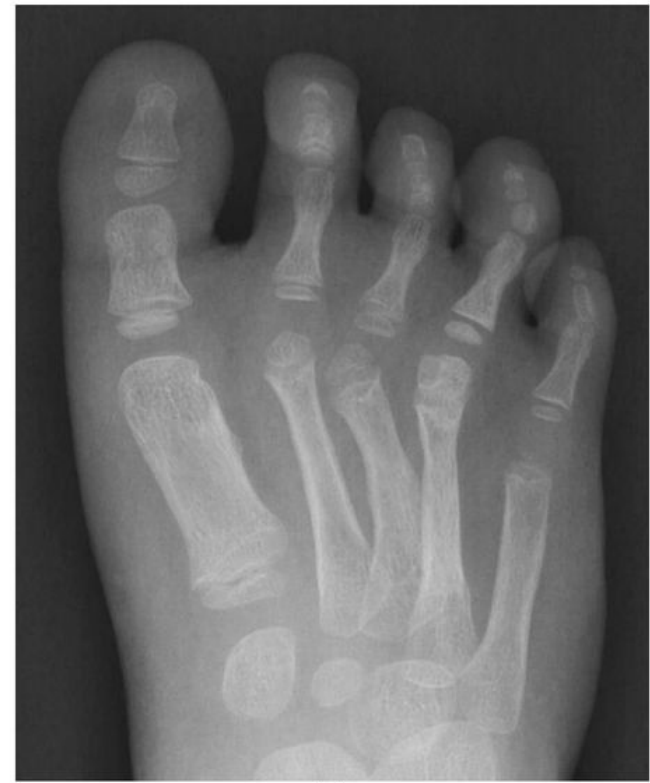

(b)

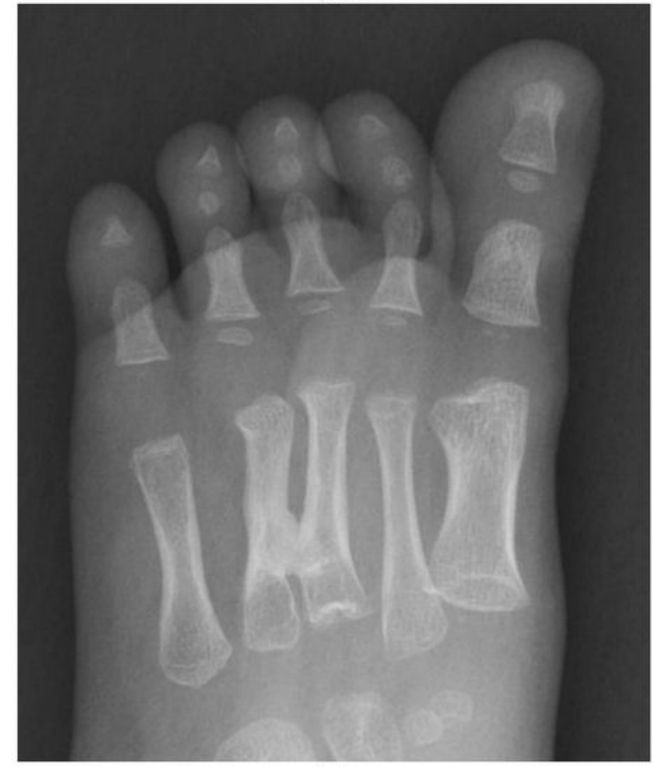

(d)

\section{Figure 4}

The radiographic findings of donor metatarsals. (a) Normal third and fourth metatarsals. (b) The lengthening of the fourth metatarsal. (c) The angulation deformity of the fourth metatarsal. (d) The synostosis between the fourth and third metatarsals.

\section{Supplementary Files}

This is a list of supplementary files associated with this preprint. Click to download.

- Additionalfile1.docx

- Additionalfile2.docx

- Additionalfile3.docx

- Table4.Scoresofthreequestionnaires.docx 